\title{
Palaeobiology and evolutionary context of Angulithes mermeti, a streamlined early Late Cretaceous shallow-water nautiloid
}

\author{
Markus Wilmsen and Emad Nagm \\ Acta Palaeontologica Polonica 64 (4), 2019: 831-894 doi:https://doi.org/10.4202/app.00637.2019
}

Cretaceous nautiloids are commonly characterized by inflated shells and prolonged stratigraphic ranges. In the Albian, the species of Angulithes appeared and compressed, short-lived forms with narrow venters emerged during the Cenomanian age. Based on a new description, the late Cenomanian nautiloid Angulithes mermeti is discussed with its palaeobiological background and placed in an evolutionary context of the Cenomanian lineage of Angulithes, considering contemporaneous palaeoenvironmental changes and inferred functional traits. A. mermeti is characterized by a nearly oxycone shell with sharp venter and narrow umbilicus, a fairly sinuous suture, low inter-septal distances, and an almost dorsal siphuncle. Its palaeobiogeographical occurrence was latitudinally restricted to shallow tropical-subtropical shelf seas with a preferred habitat depth between 5-50 $\mathrm{m}$. Several morphological trends reflected by the Cenomanian species of the genus culminated in the late Cenomanian species A. mermeti , i.e., (i) increasing shell compression and sharpening of the venter, (ii) increasing folding of the septa, (iii) reduction of inter-septal distances, and (iv) dorsally directed migration of the siphuncle. The hydrodynamically efficient form was favorable to successfully populate the wide and shallow epicontinental seas that formed during the Cenomanian age. The increasing sutural sinuosity and the dense septal spacing aimed to buttress the shells against shell-breaking predators while the functional reason for the dorsal- directed migration of siphuncle is more elusive; it may have improved the efficiency of the hydrostatic apparatus and its internal position is beneficial in the case of predation, too. The gradual morphological change in the Cenomanian lineage of the genus Angulithes provides a well-constrained case study of rapid evolutionary response to major environmental pressure, i.e., the opening of newly available niches in the course of the great early Late Cretaceous transgression, in an otherwise rather bradytelic biotic group.

Key words: Cephalopoda, Nautilida, palaeobiogeography, autecology, functional morphology, evolutionary patterns, Cenomanian, Egypt.

Markus Wilmsen [markus.wilmsen@senckenberg.de], Senckenberg Naturhistorische Sammlungen Dresden, Museum für Mineralogie und Geologie, Sektion Paläozoologie, Königsbrücker Landstraße 159, 01109 
Dresden, Germany. Emad Nagm [emad.nagm@yahoo.com], Department of Geology, College of Science, Taibah University, Madinah 41411, Saudi Arabia and Department of Geology, Faculty of Science, Al-Azhar University, Assiut 71524, Egypt.

This is an open-access article distributed under the terms of the Creative Commons Attribution License (for details please see creativecommons.org), which permits unrestricted use, distribution, and reproduction in any medium, provided the original author and source are credited.

For Full text $(1,438.0 \mathrm{kB})$ 